\title{
Erratum to "Assessment of Uinta Basin Oil and Natural Gas Well Pad Pneumatic Controller Emissions" [Journal of Environmental Protection, 2017, 8, 394-415]
}

\section{Eben D. Thoma}

Office of Research and Development, National Risk Management Research Laboratory, U.S. EPA, Durham, NC, USA

Email: thoma.eben@epa.gov

How to cite this paper: Thoma, E.D. (2017) Erratum to "Assessment of Uinta Basin Oil and Natural Gas Well Pad Pneumatic Controller Emissions" [Journal of Environmental Protection, 2017, 8, 394-415]. Journal of Environmental Protection, 8, 1445-1445.

https://doi.org/10.4236/jep.2017.812088

Received: February 12, 2017

Accepted: April 23, 2017

Published: April 26, 2017

Copyright $\odot 2017$ by author and Scientific Research Publishing Inc. This work is licensed under the Creative Commons Attribution International License (CC BY 4.0).

http://creativecommons.org/licenses/by/4.0/
The original online version of this article (Thoma, E.D., et al. (2017) Assessment of Uinta Basin Oil and Natural Gas Well Pad Pneumatic Controller Emissions. Journal of Environmental Protection, 8, 394-415.

https://doi.org/10.4236/jep.2017.84029), contained errors in Table 1 for gas and water production values. The corrected table is shown below.

Table 1. Site information and cumulative well pad production for the surveyed sites.

\begin{tabular}{cccccc}
\hline \multirow{2}{*}{ Site } & No. of Wells & Prod. Start & Oil & Water & Gas \\
\cline { 2 - 6 } & $(\mathrm{N})$ & $(\mathrm{MM} / \mathrm{YY})$ & $(\mathrm{Mbbls})$ & $($ Mbbls $)$ & $(\mathrm{Mscf})$ \\
\hline Oil 1 & 1 & $11 / 2012$ & 70.9 & 22.4 & $1.01 \times 10^{5}$ \\
Oil 2 & 2 & $07 / 2006,07 / 2014$ & 96.5 & 8.4 & $1.06 \times 10^{5}$ \\
Oil 3 & 1 & $03 / 2015$ & 32.3 & 7.6 & $2.84 \times 10^{4}$ \\
Oil 4 & 1 & $04 / 2015$ & 26.2 & 12.0 & $3.35 \times 10^{4}$ \\
Oil 5 & 1 & $01 / 2015$ & 84.4 & 40.1 & $1.86 \times 10^{5}$ \\
Gas 1 & 4 & $06 / 2000,8 / 2000$ & 6.3 & 16.8 & $2.82 \times 10^{6}$ \\
Gas 2 & 3 & $04 / 1982,12 / 1999$ & 9.4 & 12.0 & $3.30 \times 10^{6}$ \\
Gas 3 & 5 & $08 / 1983,12 / 1998$ & 9.1 & 17.4 & $4.59 \times 10^{6}$ \\
\hline
\end{tabular}

